*Mohammed Ibrahim Shire ${ }^{a *}$ and Abdi Hersi ${ }^{\mathrm{b}}$

Institute of Criminal Justice Studies, University of Portsmouth, Portsmouth, United Kingdom; ${ }^{b}$ Griffith Centre for Social and Cultural Research, Griffith University, Brisbane, Australia 


\title{
Brothers in arms: the phenomenon of complex suicide attacks
}

\author{
Abstract: \\ Globally, the spread and use of suicide bombing attacks have become a regular \\ occurrence. Security studies literature focuses primarily on conventional suicide \\ bombing attacks. However, a growing trend has been observed on the adoption of \\ complex suicide attacks. Using Al-Shabaab as a case study, this paper \\ investigates the phenomenon of complex suicide attacks. We explore the tactical \\ differences of complex suicide attacks vis-à-vis simple attacks in terms of its \\ target goal, discriminative lethality, and delivery method. The paper relies on a \\ uniquely constructed dataset of the group's suicide operations, employing a \\ variety of data collection techniques. The findings reveal that, inter alia, complex \\ suicide attacks reduce civilian casualties compared to simple suicide attacks. \\ Contrary to the group's intent and official guidelines to target foreign entities; \\ findings illustrate that domestic targets bear the brunt of most complex suicide \\ attacks. These findings have the potential to contribute to counter-terrorism \\ strategies and be adopted by concerned states in order to effectively protect \\ significant loss of lives and destruction of property resulting from suicide \\ terrorism.
}

Keywords: suicide terrorism, al-Shabaab, complex attacks, simple attacks, violent extremist organisations 


\section{Introduction}

Global terror networks continue to pose a security threat to the African continent. Amongst the most active violent extremist organisations (VEOs) in Africa are Boko Haram in Nigeria, the Tuareg group in Mali, Al-Qaeda in Sudan, Al-Qaeda in the Islamic Maghreb and Al-Shabaab in East Africa. Over the past two decades, the spread of terrorism and extremism in East Africa has intensified ${ }^{1}$. The region is home to one of Africa's most adaptable and notorious VEOs — the Harakat Al-Shabaab Al-Mujahidin (commonly known as Al-Shabaab). It is reported that this group is the cause of the most intractable terrorist threat in sub-Saharan Africa ${ }^{2}$. Al-Shabaab is associated with more violence than any other terrorist group and was recognised in 2017 by the Armed Conflict Location and Event Data Project (ACLED) as the deadliest terrorist group in Africa ${ }^{3}$.

Whilst the group is primarily active in Somalia — claiming the lives of thousands of victims in recurrent onshore attacks — it maintains operational capability and reach into the broader East Africa region ${ }^{4}$. Some notable examples of their successfully planned and executed transnational operations include the September 2013 West Gate mall attack in Nairobi Kenya ${ }^{5}$ and the July 2010 twin suicide bombing attacks in Kampala, Uganda ${ }^{6}$. Suicide attacks committed by Al-Shabaab in Somalia and the broader East Africa region continue to surge. However, it is not the rapid increase in suicide attacks that is most troubling but the salient pattern that these attacks are growing in sophistication and becoming increasingly complex.

Since 2013, Al-Shabaab has increasingly incorporated "complex" suicide attacks as part of its tactics, techniques, and procedures (TTP). Whilst a variety of definitions of the term "complex attacks" has been suggested, this paper will use the definition originally proposed by the Office of the United Nations Assistance Mission in 
Afghanistan (UNAMA) who defined it as “...a deliberate and coordinated attack that includes a suicide device, more than one attacker, and more than one tactic (for instance, a suicide vehicle bomb) and small arms fire" ${ }^{7}$. We acknowledge that prior to 2008, well-coordinated attacks executed by organised insurgents involving non-suicide IED and small arms fire were referred to as complex attacks. Conversely, we define "simple attack" as the traditional suicide bombing operation involving one or more suicide bombers but absent of any assailants. Although the use of complex operations in suicide bombings is a common feature of Al-Shabaab's TTP, several transnational terrorist groups have relied on this tactic for more than a decade. Whilst simple suicide attacks have received considerable scholarly analysis, in contrast, there is a dearth of academic literature on complex suicide attacks.

Public and political debates concerning the surge in terrorism and extremism in East Africa are ongoing. A notable level of academic and research interest has emerged in an attempt to gain an understanding of the genuine rising threat of terrorism in the region. A review of the scholarly literature reveals that this body of research is currently limited to discussions about the Al-Shabaab group's history and evolution ${ }^{8}$, ideology ${ }^{9}$, motivations ${ }^{10}$ and general targeting tactics ${ }^{11}$. Significant research is also devoted to counterterrorism narrative discourses which seek to defeat Al-Shabaab's ideology and recruitment strategies ${ }^{12}$. This paper departs from this familiar line of scholarly inquiry and looks into the phenomenon of the complex suicide attacks which the group employs.

An emerging trend of Al-Shabaab's adoption of complex suicide attacks is observed, and numerous examples include the African Union Mission in Somalia (AMISOM) base in El-Adde (15 January 2015), presidential palace, Villa Somalia (21 February 2014), Mogadishu courthouse (14 April 2013). In this paper, we contend that 
the phenomenon of complex suicide attacks escapes crucial empirical examination in a vast body of suicide terrorism literature. This is despite the fact that Al-Shabaab is increasingly becoming reliant on using the tactic of complex suicide attacks. We also believe it is imperative to understand and learn about the dynamics of complex suicide attacks so that policymakers can remain better informed when formulating counterterrorism strategies.

To fill this gap, this paper aims to address the following research question: how fundamentally different are complex suicide attacks from simple suicide attacks in terms of target goal, discriminative lethality, and delivery methods?

The remainder of this paper proceeds as follows. In the following section, we introduce contextual information about the strategic and tactical efforts of suicide bombings. We specifically theorise the motivation behind the adoption of complex attacks using Al-Shabaab as a case study. We then present our unique constructed dataset that tracks Al-Shabaab's suicide bombing operations from 2006 to 2018 . The following sections present our results and discuss the key findings. We conclude the paper by outlining the implications of these findings for both academic and policy audiences.

\section{Dying to kill}

Studying suicide terrorism has become an important aspect of international focus, given the ongoing insurgencies in the Middle East and Africa. Indeed, for more than three decades, suicide bombings — and the pervasive, unpredictable threat of such attacks - have captured the attention of the global media because of their higher fatality rates, catastrophic destruction, and widespread terror ${ }^{13}$. As is now common amongst many present-day VEOs, perpetrators have developed sophisticated TTPs for conducting these attacks, which have occurred on land, sea, and in the air. Dolnik ${ }^{14}$ 
believes that suicide attacks are the "ultimate terrorist tactic" and that they are the most dominant, fastest-spreading type of terrorist attack across Africa and the Middle East. Suicide bombings can be conducted for a variety of reasons - political, religious or ideological — and they may be carried out for tactical or symbolic purposes ${ }^{15}$. More than other tactics, suicide bombings are "devastatingly effective, lethally efficient, have a greater likelihood of success, and are relatively inexpensive and generally easier to execute than other attack modes" ${ }^{16}$. The purpose of suicide bombings is often to strategically coerce the state to make concessions about territory or governance ${ }^{17}$.

The actual deployment of suicide bombings has become much more sophisticated over time, as can be seen from more massive, coordinated attacks, and attacks by groups in foreign countries (such as 9/11). For instance, beginning in the year 2000, Chechen terrorists were the first to use large scale barricade hostage-taking operations in conjunction with suicide bombers. Often, groups purposefully choose to conduct such attacks instead of using other TTPs because they are perceived as being "effective". Success, or lack of it, however, is less relevant to terrorist groups when deciding whether or not to conduct suicide attacks.

Between the late 1980s and early 1990s, suicide bombings were identified as a phenomenon rooted in irrationality ${ }^{18}$. However, these early assumptions, hitherto the dominant paradigm in terrorism studies ${ }^{19}$, have been rejected by recent studies, and an updated strategic model has been introduced. The current strategic model explains terrorist behaviour through a rationalist lens. It is based on key parameters that include motivations based on political preferences. This implies that terrorists evaluate the potential benefits of the choices available to them, and adopt violent tactics when the perceived benefits are greater than those apparent through other available options. An 
insurgent group may opt to conduct suicide attacks for a variety of strategic and tactical reasons, and this has been widely discussed in literature ${ }^{20}$.

One growing voice that looks beyond the irrational/rational debate is the focus on religion as an important factor when groups conduct suicide attacks ${ }^{21}$. Indeed, Berman and Laitin ${ }^{22}$ argued that suicide attacks were executed more successfully when employed by religious organisations. Henne ${ }^{23}$ finds that religious insurgent groups place a greater emphasis on indiscriminately killing as many people as possible and as such were more likely to carry out suicide attacks. Religious insurgent groups, especially when they are also orientated as ethnonationalist in organisation (e.g., Al-Shabaab) launch deadlier attacks. This performance of violence is partly motivated to impress a supernatural audience ${ }^{24}$.

As terrorist groups continue to become increasingly innovative and effective, suicide attacks continue to be instrumental in challenging and attacking governing authorities for years to come.

\section{Complex suicide attacks: an unexplored phenomenon}

The empirical literature on terrorism has abundant studies on simple suicide bombings. However, there is a scarcity of academic studies on the phenomenon of complex suicide attacks, even though the employment of complex operations is now ubiquitous amongst terrorist organisations around the globe. The Taliban conducted the first example of a complex attack on 14 January 2008 when a group of four Taliban members, using suicide bombs, grenades, and automatic rifles attacked the Serena Hotel in Kabul, Afghanistan, killing six people and wounding six others. Henceforth, several VEOs, including Lashkar-e-Jhangvi, Islamic State and Al-Qaeda, have employed this type of tactic. 
In more recent incidents of suicide terrorism, a pattern has emerged where complex attacks that target military bases or other government structures start with a suicide bomber in order to break through the initial line of defence. This complex attack allows additional assailants, either more armed suicide bombers or attackers armed with firearms or other weapons, to swarm or raid the desired target. Since suicide bombings cause mass destruction and chaos, employing them as part of complex attacks helps to focus these defences on a specific area, thereby weakening defences in other parts of the targeted entity.

From a hard target's perspective, it also makes sense that these more fortified structures and targets are more difficult to attack with a single assailant, or with a single bomber. The inclusion of several assailants with a number of different weapons allows for a higher likelihood of success. Hoffman's ${ }^{25}$ assessment of suicide bombers as the ultimate smart bomb, by including a suicide bomber in complex attacks, makes sense strategically and tactically. Such a tactic allows the bomber to identify and strike the weak point of the intended target's security. For instance, Kliot and Charney ${ }^{26}$ discovered that the building of the Israeli West Bank barrier changed the attack patterns of suicide bombers. Specifically, the authors found that bombers carried out attacks in areas where the fence was incomplete. Previous examinations of observational patterns suggest that suicide bombings in complex attacks are merely used as tactical tools against hard targets and weakened defences of a targeted entity. Importantly, these insights do not answer fundamental questions about the dynamic differences in relation to simple attacks, in terms of target goal, discriminative lethality and delivery methods. We seek to fill this gap in the literature through a case study on Al-Shabaab, one of the deadliest terrorist groups in Africa that relies heavily on complex suicide operations. 
As we aim to investigate how complex suicide attacks differ from simple suicide attacks in terms of target, lethality, and delivery, it is important that we hypothesise why Al-Shabaab might employ complex suicide attacks in lieu of simple suicide attacks by looking at the target goal, discriminative lethality, and delivery methods. To investigate this, the following sections will briefly discuss the theoretical underpinnings of why AlShabaab might utilise complex suicide attacks to explicitly target foreign forces in Somalia, enhance precision in lethality and deploy sophisticated delivery methods.

\section{Target goal}

One cannot deny that suicide terrorism is often perceived as successful in achieving the immediate objectives of VEOs. Following the Marine Barracks Bombing in Lebanon in 1983, US President Reagan ordered the withdrawal of American troops within four months ${ }^{27}$. This is one of the many examples of the perceived success of suicide attacks supporting the strategic argument for suicide terrorism. In considering the ratio of terrorists killed to enemy victims associated with suicide terrorism, the justification for the use of this tactic against a superior combatant force is clear. Pape notes a correlation in his research between foreign military occupation and an increase in suicide terrorist activity ${ }^{28}$. Pape expounded that the rise of suicide bombings is related to nationalist sentiment seeking to drive out foreign occupying forces, primarily when the foreign occupiers are of a different religion and are seen as promoting ideals of liberal democracy ${ }^{29}$. A relationship between suicide bombings and foreign occupation has been substantiated and acknowledged in a number of case studies, and several authors have proposed that suicide bombing is a result of foreign occupation ${ }^{30}$. VEOs adopt this tactic to raise the ante against the foreign occupier whilst simultaneously raising the media profile of their campaign, thus pressuring the occupier into leaving. 
Suicide bombings in East Africa started gaining in trajectory the moment Ethiopia invaded Somalia in December 2006. Ethiopia ended its two-year occupation of Somalia in 2009, and its occupation was replaced by AMISOM. At this time, A1Shabaab shifted the foreign occupier tag to AMISOM forces. AMISOM was initially deployed in Somalia in March 2007 to, inter alia, reduce the threat posed by Al-Shabaab and other armed groups. Its military component comprised troops from Burundi, Sierra Leone, Djibouti, Ethiopia, Kenya and Uganda. Given that Ethiopia, Kenya, and Somalia share a long and complex history riddled with mutual fear, suspicion and territorial expansionist ideologies, it is ironic that the same Ethiopian and Kenyan troops who invaded Somalia in 2011 were redeployed as part of AMISOM in 2012 and 2014.

This is compounded by the fact that journalists and politicians frequently describe the AMISOM mission as a "peacekeeping" deployment, tasked to conduct “peace support operations" and protect Somalia's fragile government. However, AMISOM as a peacekeeping mission does not conform to the three basic principles that define peacekeeping — impartial non-use of force except in self-defence, the consent of the warring parties and the defence of a mission's mandate. Consequently, Al-Shabaab refuses to approve of the presence of AMISOM forces, as the mission was unquestionably established to lend support to Somalia's government. AMISOM units have implemented offensive combat postures, and have mounted attacks against AlShabaab's strongholds. Al-Shabaab categorically made clear in their communication that their primary targets are these foreign entities:

Ethiopians, Kenyans, Ugandans, and Burundians are just like the English and the French because they have invaded the Islamic country of Somalia and launched a war on Islam and Muslims. The Experience of Our Brothers in Somalia, undated, p. 6. 
Al-Shabaab's focus on targeting foreign entities is reinforced by the directives adopted by its umbrella organisation, Al-Qaeda, which has clear rules about the admissibility of targeting using suicide bombers. Al-Shabaab obligated itself to alQaeda with its first pledge of allegiance in 2012. Al-Qaeda's central management set forth instructions as to how it should execute its attacks, being explicit in its guidelines when it comes to targeting individuals and entities. In 2013, in the group's “General Guidelines for Jihad" ${ }^{31}$ Al-Qaeda's leader, Ayman al-Zawahiri, issued directives that advise Al-Qaeda affiliated groups how to conduct certain attacks and how they should participate in "proper jihad". In particular, Al-Qaeda's branches, affiliates, and allies must avoid targeting those that are not at war with them, and must primarily focus on targeting the Crusader Alliance and secondarily focus on their local surrogates. Secondly, attacks against enemies that are housed in mosques, public gatherings where they mix with Muslims, or those who have not raised arms against them should be avoided ${ }^{32}$. Al-Shabaab has failed to adhere to these general rules of engagement. Its relentless targeting of civilian populated areas such as hotels and restaurants is a sign of desperation, and clearly shows the group's inability to drive AMISOM forces out of Somali territory. Al-Shabaab's alternative strategy appears to be making the territories controlled by the Somali federal government and its member states ungovernable.

Complex suicide attacks require sophisticated planning and resources and are renowned for their precision. Al-Shabaab has received sharp criticism for deviating from Al-Qaeda's ethos of avoiding civilian targets and for its focus on foreign occupation forces. For the purposes of this study, an important and pertinent inquiry is the extent to which Al-Shabaab incorporates complex suicide attacks to specifically target foreign occupation forces such as AMISOM in Somalia, and avoids civilian targets or places 
where civilians and non-civilians mix, such as hotels and restaurants. Consequently, we expect that that our data would reveal a significant sharp increase in targets against foreign forces.

\section{Discriminative lethality}

It is important to note that there was initially disappointment from Al-Qaeda's central leadership about how Al-Shabaab conducted its suicide attack operations. Al-Qaeda was quick to express its displeasure when the group overstepped its boundaries and made mistakes, such as attacking the Shamo Hotel in Mogadishu during a graduation ceremony for medical students in 2009. Al-Qaeda's principal founder, Osama bin Laden, swiftly reproached Al-Shabaab for its callous targeting. Indeed, Al-Qaeda delineated clear rules for its "martyrdom operations" and the group has levelled plentiful criticism against Al-Shabaab for its intentional targeting of civilians.

More precisely, various letters gleaned during the raid on bin Laden's house in Abbottabad, Pakistan in 2011, revealed Al-Qaeda's appeals to Al-Shabaab to steer clear of targeting civilians. One letter, composed in 2007, earnestly appealed to its recipient: "Please talk to the Somali brothers about reducing the harm to Muslims at Bakarah Market as result of attacking the headquarters of the African forces...Instead, they should focus on attacking them on their way to and from the airport" 33.

Considering that simple suicide attacks incur a high civilian/non-civilian casualty ratio, we expect that our data would show that Al-Shabaab employs complex suicide attacks as a means to improve precision and adhere to Al-Qaeda's clear rules in reducing civilian fatalities.

\section{Delivery methods}

VEOs employ diverse tactics, techniques and procedures (TTPs). Some successful 
tactics - many of which are well-suited to urban environments — include the use of ambushes, IEDs or suicide bombs, arson, assassinations, kidnappings, extortion, and missiles ${ }^{34}$. However, the choice of tactics, targets and weapons is influenced by a group's ideology, internal dynamics, leadership, and the environment ${ }^{35}$. Surprisingly, there remain significant gaps in the literature concerning the preferred weaponry of militants. This is more true for academic discussion on suicide IEDs, where it has been heavily asserted that they have become the weapon of choice for VEOs around the globe ${ }^{36}$. Most authors do not mention this type of weapon at all, whilst others acknowledge that IEDs are threats and will continue to remain so but provide few (if any) details as to their construction and tactical employment ${ }^{37}$.

Suicide attacks predominantly employ suicide belts (commonly referred to as person-borne improvised explosive device (PBIEDs)), used by perpetrators who approach their targets on foot, or suicide vehicle bombs (commonly referred to as suicide vehicle-borne improvised explosive devices (SVBIEDs)) which involve a driver who steers a vehicle laden with explosives towards a target. The latter method tends to use civilian cars, minibuses, and trucks and allows for the covert delivery of larger charges into a target area, as the explosives can be concealed in the vehicle. Considering that complex suicide attacks are defined as attacks that employ multiple hostile elements and different weapon systems, we expect that our data would show that AlShabaab will predominately deploy more motorised weapons such as explosive-laden vehicles, cars or truck bombs in their complex operations.

\section{Methods}

\section{Dataset}

We constructed a unique dataset of Al-Shabaab suicide bombings, employing an 
assortment of data collection techniques. The dataset includes 208 incidents from September 2006 until the end of December 2018. We included any suicide attack where Al-Shabaab claimed responsibility or where at least two sources attributed blame to the group. The sources who attributed blame to the group were carefully and objectively considered. Each suicide attack incident included information on the country and city/town/village of incident, the number of civilian and non-civilian fatalities and injuries, target type, hard or soft target, type of IED, the number of perpetrators, gender, whether it was a complex or a simple attack and instances of non-detonation or prevention of suicide attacks, amongst others. The dataset originally was formulated based on the skeleton dataset of the Global Terrorism Database (GTD). However, we found that it was missing the years 2006-2009 and 2017-2018 and that the database erroneously attributed suicide bombing attacks perpetrated by other Somalia based Islamist militant organisations (e.g., Hizbul Islam) to Al-Shabaab. Furthermore, we noted that the database made no distinction between complex and simple suicide attacks.

To remedy this, we have expanded the data from the original seven variables and added the missing years (2006 to 2009 and 2017 to 2018) by comparing entries with data drawn from Factiva. We culled online newspaper stories containing the search strings Al-Shabaab OR Al-Shabab AND bomb OR bombing and filled the missing years with data acquired from news articles. We iteratively went through the data, and to maximise the reliability of data, we extensively cross-referenced and validated it with news sources in the English and Somali languages from September 2006 to December 2018. We analysed the news articles from when the first suicide attack was reported and from the subsequent 15 days to accurately plot the latest casualty figures. A comprehensive database was created based on our coding detailing 20 variables of each 
suicide bombing (which includes, inter alia, different types of fatalities, delivery systems, gender, claimed by Al-Shabaab), where such data was available. As a caveat, our data and subsequent verification checks regarding fatalities should be viewed as minimums, with the actual numbers being possibly higher.

\section{Juxtaposition of simple suicide attacks and complex suicide attacks}

\section{Al-Shabaab's general suicide operations}

Our dataset reveals that from the group's first deployment of suicide bombing in September 2006 up until December 2018, we find 208 instances of suicide bombing deployed by Al-Shabaab involving 277 individual bombers. Out of the 208 total suicide attacks, 54 were complex suicide attacks. Based on our dataset - which we believe to be the best available data on the Al-Shabaab group - we reveal that to date, Al-Shabaab's suicide operations have claimed, at a minimum, 2,979 (excluding the lives of the bombers, which adds another 277) suicide bombing related deaths.

In assessing the lethality of suicide bombing operations, the majority of studies calculate it as the number of fatalities per attack or operation. The University of Chicago's dataset estimates that between 1974 and 2016 there were a total of 5,430 suicide attacks causing 55,022 deaths, which indicates that the average suicide bombing operation killed 10.13 people. Al-Shabaab's average lethality stands at 14.32 fatalities per attack, far higher than the world's average. However, the average number of fatalities per suicide attack is slanted upward as a result of the Zoobe October 2017 suicide attack in Mogadishu, which killed 587 people. This single attack represents the world's deadliest terrorist attack since the September 11 twin tower bombings in New York, US. Omitting this outlier event, its lethality rate per attack falls to around 11.5 
deaths per attack, which is still higher than the approximate average amongst global groups using suicide bombing.

Our data show that after the group's first inroad into suicide bombing, it did not consistently deploy suicide bombers for several years (see Table 1). Indeed, from 2006 to 2010, Al-Shabaab averaged less than one suicide operation per month. The intermittent use of suicide bombing during the early stages of Al-Shabaab's operations can be clarified by the group's efforts to hold its territorial holdings in Somalia against external actors. The Ethiopian army and other international actors have sought to regain control of both Mogadishu and Al-Shabaab's strongholds in the southern port city of Kismayo. As a result, in its effort to maintain its holdings, Al-Shabaab focused on waging conventional warfare rather than resorting to the more asymmetric tactic of suicide bombing.

Table 1. Al-Shabaab's suicide bombing operations over time

\begin{tabular}{|l|r|r|r|r|r|r|r|r|r|r|r|r|r|r|}
\hline & 2006 & 2007 & 2008 & 2009 & 2010 & 2011 & 2012 & 2013 & 2014 & 2015 & 2016 & 2017 & 2018 & Total \\
\hline January & & & & & 1 & & 2 & 3 & 1 & 2 & 3 & 3 & & 15 \\
\hline February & & & & 1 & 1 & 1 & 2 & 1 & 2 & 1 & 4 & 2 & 2 & 17 \\
\hline March & & 1 & & & & & 1 & 3 & 3 & 1 & 2 & 4 & 3 & 18 \\
\hline April & & 1 & 1 & & & & 2 & 1 & & 3 & 1 & 2 & 4 & 15 \\
\hline May & & & & 1 & 1 & 1 & 1 & 1 & 3 & 1 & 3 & 3 & 1 & 16 \\
\hline June & & 4 & & 1 & & 2 & 1 & & 1 & 4 & 4 & 5 & 1 & 23 \\
\hline July & & 1 & & & 2 & & & 2 & 4 & 4 & 4 & 1 & 1 & 19 \\
\hline August & & & & & 1 & 1 & 1 & & 2 & 3 & 3 & 2 & 2 & 15 \\
\hline September & 1 & & & 1 & 1 & 1 & 2 & 2 & 1 & 3 & 1 & 5 & 2 & 21 \\
\hline October & & 1 & 5 & & & 4 & 1 & 2 & 2 & & 5 & 3 & 2 & 25 \\
\hline November & 1 & & & & & 1 & 1 & 1 & & 3 & 2 & 1 & 3 & 13 \\
\hline December & & & & 1 & & 1 & 1 & 1 & 2 & 1 & 3 & 1 & 1 & 12 \\
\hline Total & 2 & 8 & 6 & 5 & 7 & 12 & 15 & 17 & 21 & 26 & 35 & 32 & 22 & 208 \\
\hline
\end{tabular}

In 2009, Al-Shabaab deepened its ties with Al-Qaeda but did not formally merge with the organisation. Consequently, it began expanding and increasing its suicide bombing tactics as it began to focus on using new means to assist in its primary push to 
capture Somalia's capital city, Mogadishu, and develop a footprint outside Somalia's borders. With an influx of recruits and higher prestige, suicide bombings seemed to become a more practicable option in its arsenal of violence. As AMISOM sought to launch offensives and expand outward, Al-Shabaab increased its person-borne IED and suicide vehicle bombs attacks to halt any forward progress. In 2011 Al-Shabaab applied considerable force in response to pressure from external actors, by including the adoption of suicide bombings. The group's suicide bombings increased steadily over this period, from less than five attacks per year to one bombing per month.

Since February 2012, when it officially merged with Al-Qaeda, the number of complex attack operations has steadily increased each year. The year with the highest number of Al-Shabaab's suicide bombings was 2016, with a total of 35, or 3 per month. Since our data extends to December 2018, we see that the group was on track to experience a significant weakening in its use of bombings in the year 2018 to less than two per month.

The group's investment in suicide bombing may have ties to Ethiopia's military intervention in Somalia in December 2006. In addition to Al-Shabaab's expanding coercive military power, the years 2010 and 2011 saw a significant increase in the group's propensity to use suicide bombings against both Somali and international targets. The group progressively deployed several suicide bombers to attack the same target, probably to increase degradation. In Figure 1, we illustrate Al-Shabaab's suicide bombing operations since its inception in 2006 up to December 2018. 


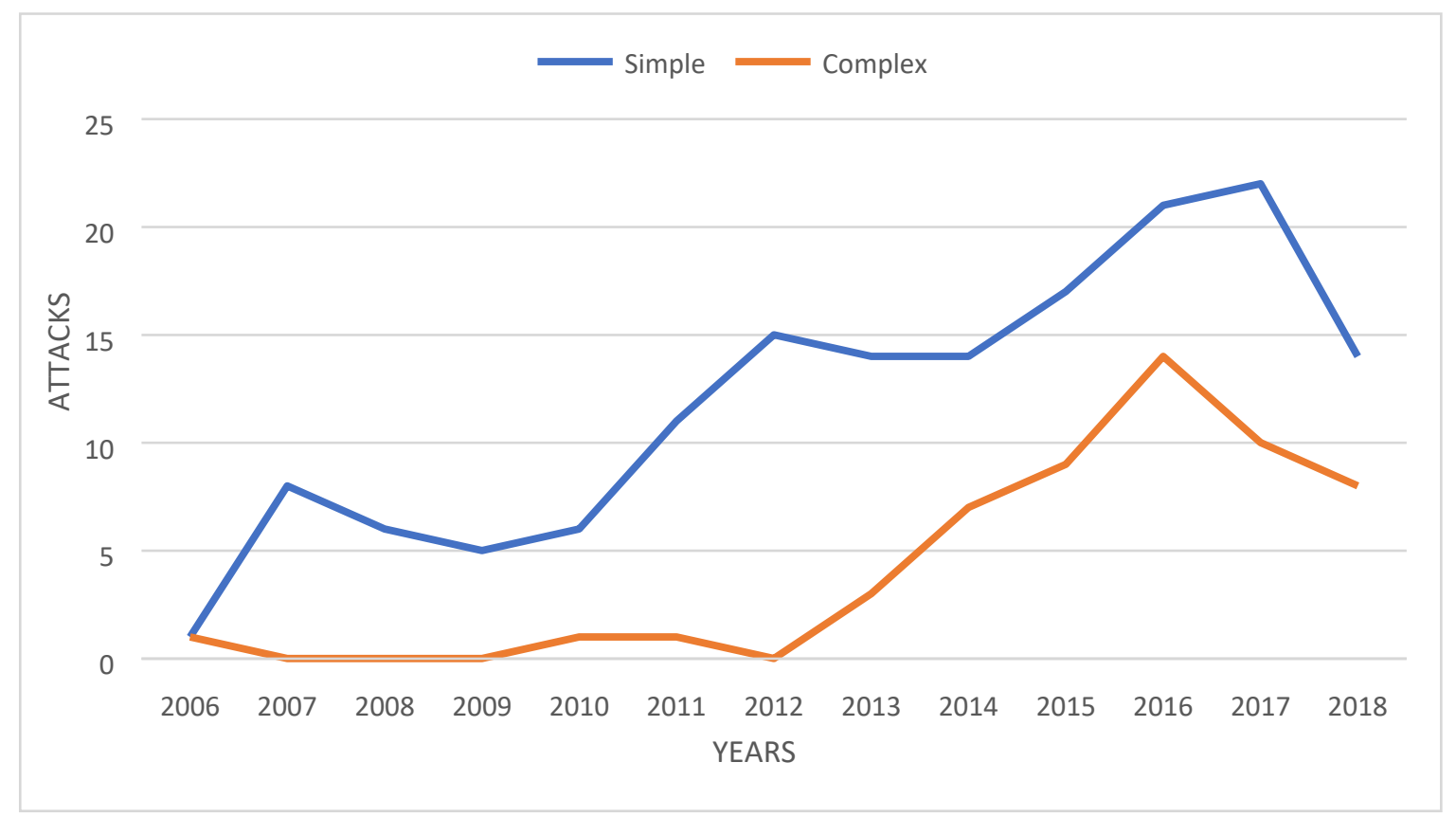

Figure 1. Timeline of simple and complex attacks

Al-Shabaab's first bombing operation in 2006 was a complex attack involving both suicide bombers and lightly armed infantry. The tactic was used to assassinate then Somali president, Abdullahi Yusuf. A suicide bomber driving a car bomb smashed into Yusuf's convoy outside the National Parliament in Baidoa, Somalia. The attack killed four of Yusuf's bodyguards as well as Yusuf's brother. Six Al-Shabaab attackers were also killed in the ensuing gun battle. Despite the apparent success of the attack, the group did not attempt another complex suicide operation for more than three years. In August 2010, Al-Shabaab mounted another complex suicide attack that targeted the Muna Hotel in Mogadishu. Al-Shabaab assailants dressed as Somali government security personnel attacked the building where a two-hour gun battle ensued until one of the gunmen detonated his explosive vest. The attack claimed the lives of 32 people, including prominent members of Somalia's parliament. 
Up until the start of 2013, a common pattern in Al-Shabaab's suicide operations was that the suicide bomber was the focal point of the operation. Gunmen generally played a supporting role, wherein they breached the security perimeter and ensured that the suicide bombers reached their objective. Following the successful operations adopted by their international counterparts such as the Taliban, Al-Shabaab modified their formula in early 2013, deploying suicide bombers to weaken the initial line of protection, whilst assailants equipped with small arms entered the premise and did most of the killing.

\section{Target}

In simple attacks conducted between 2006 and 2018 (see Figure 2), the targeting patterns reveal that Somali federal government institutions and personnel account for 39 percent of the total simple targets. The next most frequented targets were places patronised entirely by civilians, and these accounted for 15.1 percent of total targets. One example of such a place was a local market in the town of Wanlaweyn where a person-borne IED killed at least 14 people and wounded more than 15 others. Between the years 2006 and 2011, the pattern of simple attacks began with a focus on Somali federal government institutions, Ethiopian and African Union (AU) bases. It was only after 2012 that Al-Shabaab began changing its pattern and started targeting civilians whilst intensifying its attacks on the federal government of Somalia. Conversely, the primary targets of complex attacks (see Figure 2) are Somali federal government institutions and personnel, accounting for 46.2 percent of total complex attacks. The second most targeted entity are the hotels which Al-Shabaab alleges were frequented by government officials. These attacks accounted for 21.2 percent of total complex attacks whilst AU bases were the third primary target, standing at 19.2 percent of total complex 
attacks. After merging with Al-Qaeda in 2012, Al-Shabaab adopted the use of complex attacks, employing them steadily against the groups mentioned above.

In the case of simple attacks, 28.8 percent of attacks allegedly carried out by AlShabaab were not claimed by the group. Security forces thwarted close to 43 percent of these failed attacks or the suicide bomber(s) detonated them prematurely. However, in complex attacks, only two incidents were unclaimed, one of which was a failed attack.

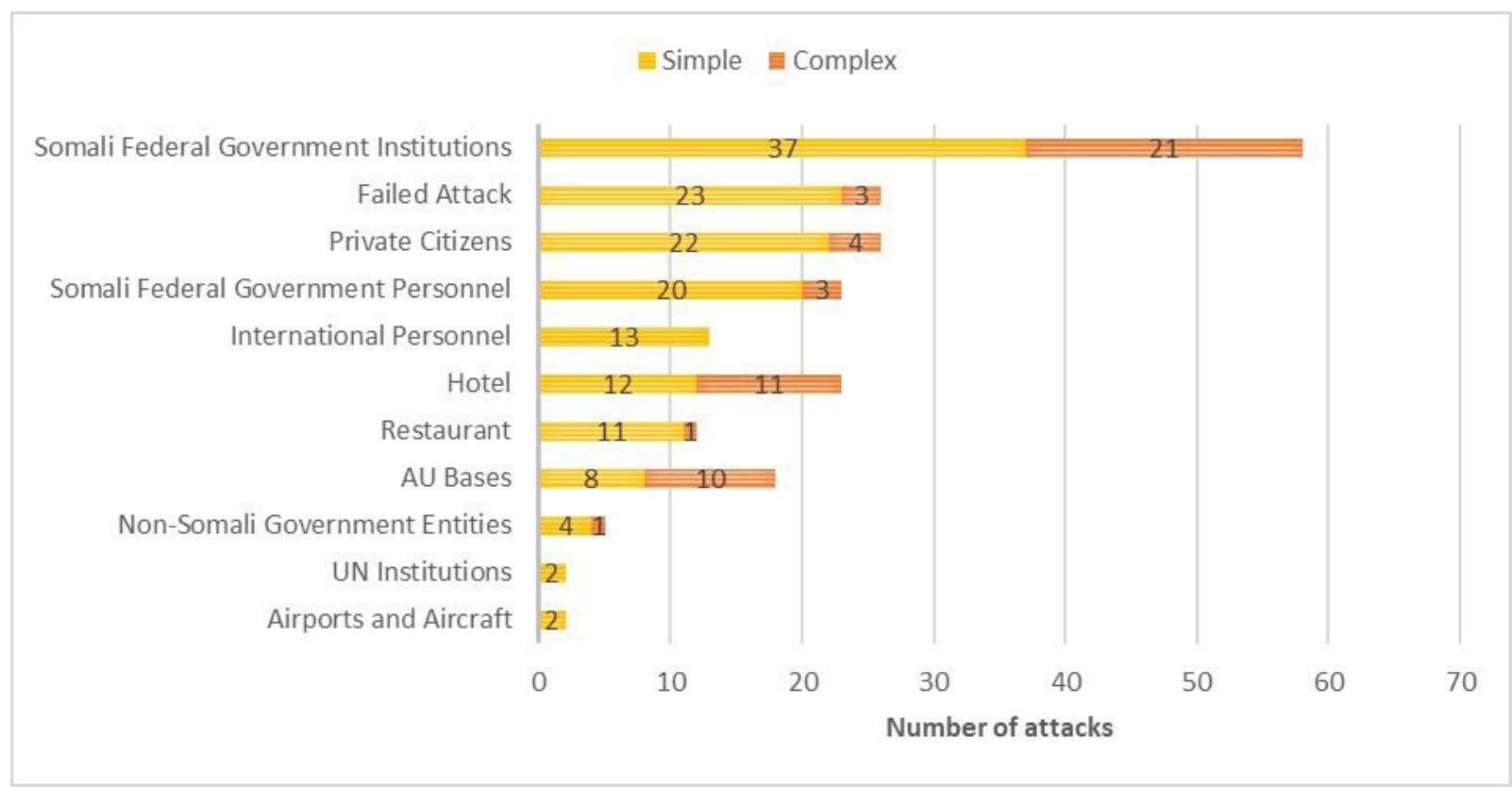

Figure 2. Al-Shabaab suicide attacks per target

\section{Lethality}

Our data reveals that with simple attacks, the average lethality per attack on noncivilians is 2.04 deaths per attack, whereas, for civilians, it is 9.36 fatalities per attack (see Table 2). The combined average lethality is 11.40 deaths per attack. This low average lethality rate is supplemented by the number of failed attacks for this particular mode. A total of 23 simple attacks (14.94 percent), almost one-sixth of the total number of attacks, detonated prematurely, thus killing the suicide bomber(s), or the attacks were foiled by security forces. The simple attacks account for almost three quarters (74.04 
percent) of Al-Shabaab's total suicide operations to date. Whilst Al-Shabaab has targeted more hard targets in carrying out simple attacks, the yearly data reveal that civilian fatalities are always higher than the non-civilian fatalities. Indeed, the civiliancombatant death rate for simple attacks reveals that 82 percent of all casualties were civilians and only 18 percent were combatants.

Conversely, in complex attacks, the average lethality per attack for non-civilians was measured at 14.3 deaths per attack, whilst for civilians, it stood at 9.40 deaths per attack, with a total success rate of 94.23 percent. The combined average lethality was measured at 23.5 fatalities per operation. Between 2012 and 2014, when complex attacks were slowly being introduced, civilian fatalities significantly outweighed noncivilian casualties. From 2014 the rate of fatalities for non-civilians was significantly higher than for civilians. Statistics for the year 2018 reveal that there were more civilian deaths than non-civilian deaths, for the first time since the adoption of the tactic.

However, the overall civilian-combatant death rate reveals that there were more combatants' fatalities (60 percent) than civilian casualties (40 percent).

Table 2. Lethality of simple and complex attacks

\begin{tabular}{|c|c|c|c|c|c|c|c|}
\hline Type & $\begin{array}{c}\text { Lethality per } \\
\text { attack } \\
\text { (combatants) }\end{array}$ & $\begin{array}{c}\text { Lethality } \\
\text { per } \\
\text { attack } \\
\text { (civilians) }\end{array}$ & $\begin{array}{c}\text { Total } \\
\text { lethality } \\
\text { per } \\
\text { attack }\end{array}$ & $\begin{array}{c}\text { Lethality } \\
\text { per } \\
\text { attacker }\end{array}$ & Bombers & $\begin{array}{c}\text { Hard/Soft } \\
\text { targeting } \\
\text { patterns rate } \\
\text { (\%) }\end{array}$ & $\begin{array}{c}\text { Combatant - } \\
\text { civilian rate } \\
\text { (\%) }\end{array}$ \\
\hline $\begin{array}{c}\text { Simple } \\
\text { attacks }\end{array}$ & 2.04 & 9.36 & 11.4 & 9.76 & 190 & $55 / 31$ & $18 / 82$ \\
\hline $\begin{array}{c}\text { Complex } \\
\text { attacks }\end{array}$ & 13.61 & 9.06 & 22.67 & 14.07 & 87 & $65 / 30$ & $60 / 40$ \\
\hline
\end{tabular}

\section{Delivery}

Al-Shabaab uses a mixture of delivery systems to conduct their simple and complex attacks. Of the 154 simple attacks (see Figure 3) conducted by Al-Shabaab, 64.29 percent events involved suicide vehicle bombs whilst 31.17 percent incorporated only person-borne IEDs. Only 4.55 percent utilised both devices in their simple attacks. 


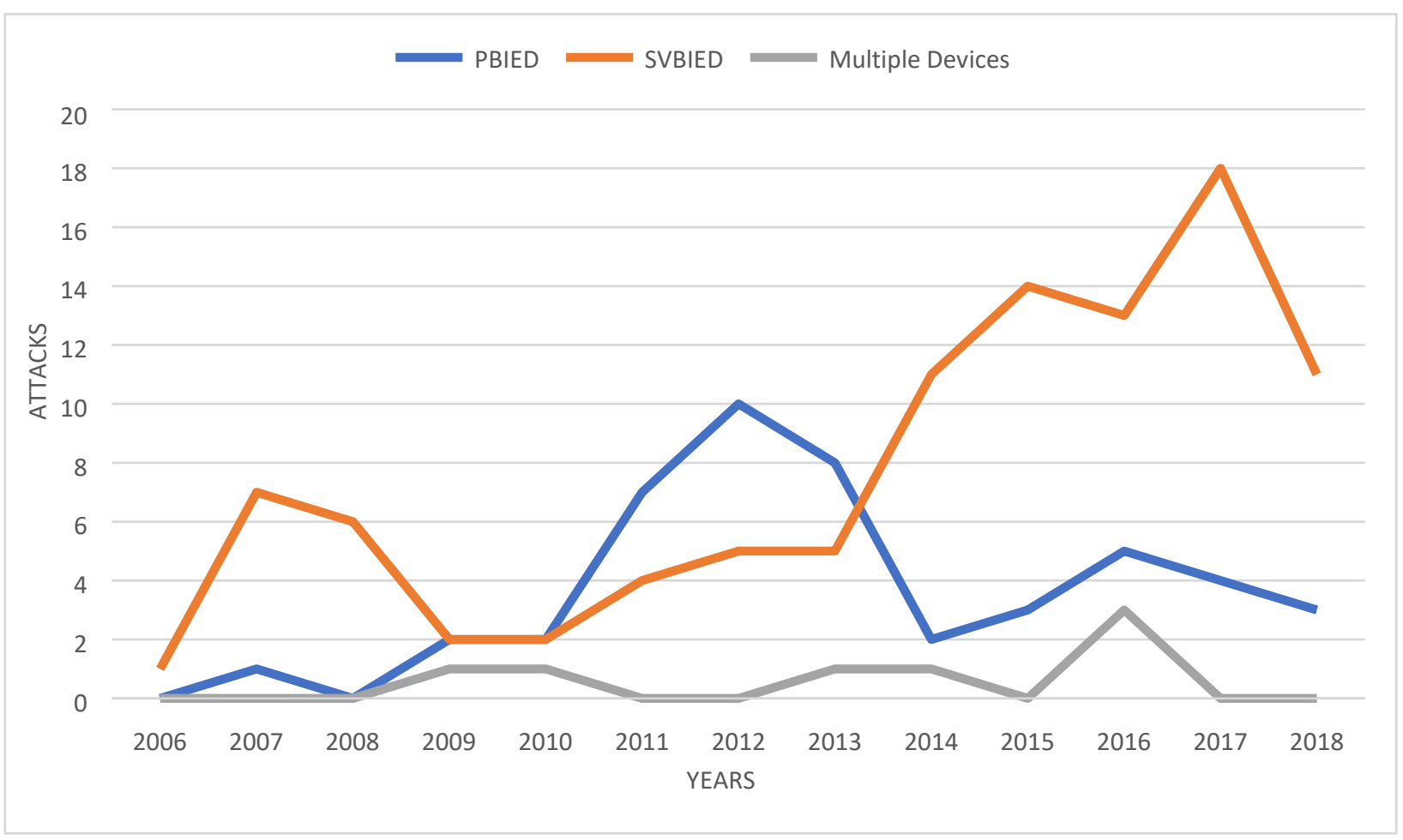

Figure 3. Timeline of delivery methods in simple attacks

Al-Shabaab introduced their simple attacks with suicide vehicle bombs in 2006, and the use of person-borne IEDs was relatively low at the time. However, from 2009, the number of person-borne IEDs and suicide vehicle bombs used in attacks were balanced and this is most noticeable between 2009 and 2011. From 2011 up to 2014, Al-Shabaab relied on person-borne IEDs as their main delivery system. The year 2014 revealed a significant drop in the use of person-borne IEDs in simple attacks, with a substantial gradual adoption of suicide vehicle bombs whilst person-borne IEDs were being phased out. One possible explanation for this is that between 2012 and 2013, a total of 8 instances of failed attacks were recorded for simple attacks, with 87.5 percent being operations where only person-borne IEDs were employed. Consequently, to decrease the number of failed attacks, Al-Shabaab placed greater weight on utilising SVIBEDs in all their future simple attacks. This is evident in 2017, where suicide vehicle bombs accounted for 77.7 percent of all simple attacks. 
Conversely, in 54 complex attacks (see Figure 4) the group relied heavily on suicide vehicle bombs. Indeed, 74.07 percent of all complex attacks employed suicide vehicle bombs whilst a mere 5.56 percent adopted person-borne IEDs. A significant percentage (20.37 percent) used both devices when carrying out complex attacks.

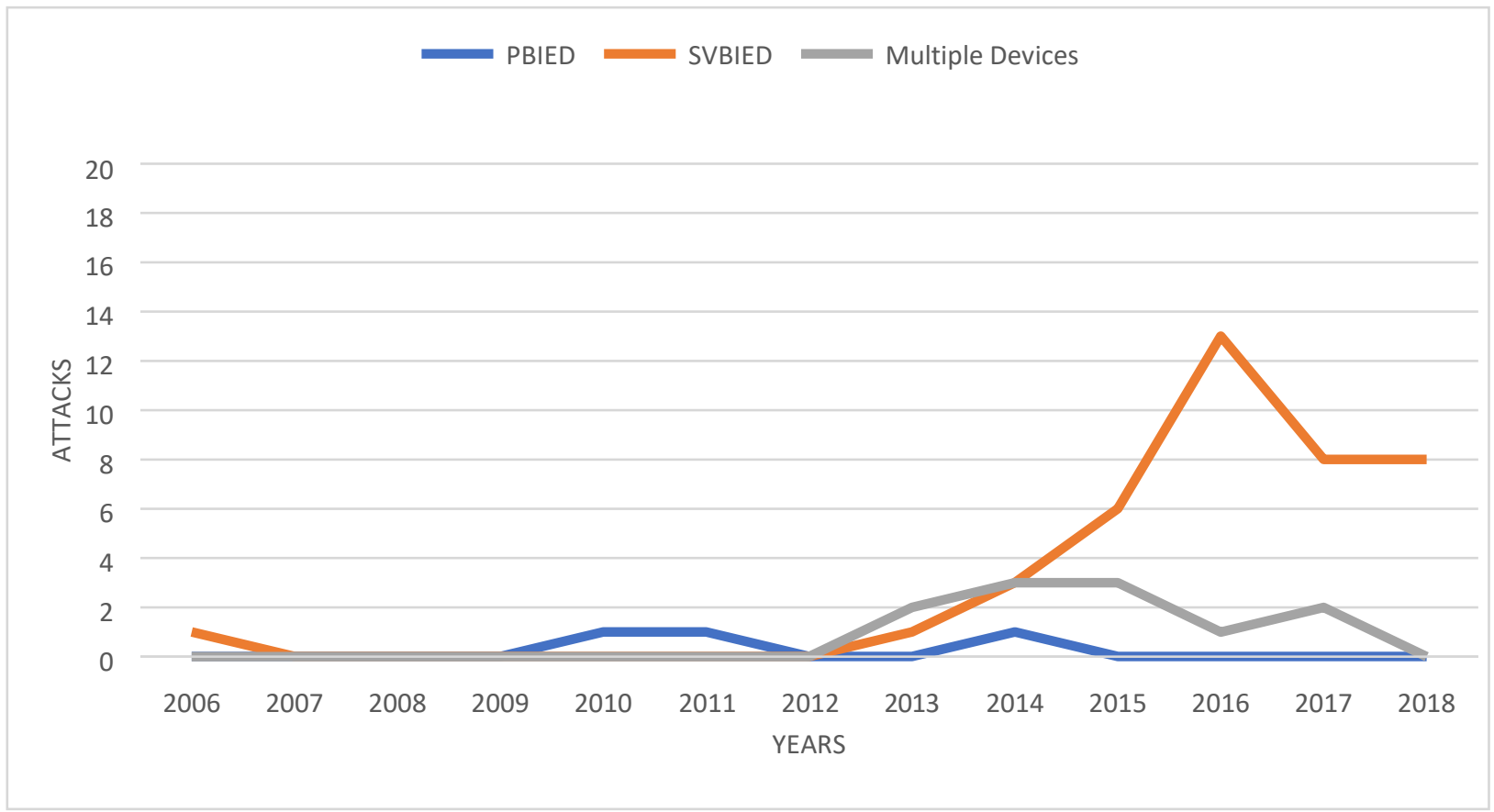

Figure 4. Timeline of delivery methods in complex attacks

Al-Shabaab's initial foray into the use of complex attacks primarily adopted the use of person-borne IEDs. Only after 2012, when Al-Shabaab officially joined AlQaeda, did they predominantly adopt suicide vehicle bombs as their main delivery system, using person-borne IEDs only on one occasion in 2014. To date, suicide vehicle bombs remain the dominant delivery system for both modes.

Table 3. Delivery methods in simple and complex attacks

\begin{tabular}{|c|c|c|c|c|}
\hline Type & Total \# & PBIED Count & SVBIED Count & Multiple Devices Count \\
\hline Simple attacks & 154 & $48(31.17 \%)$ & $99(64.29 \%)$ & $7(4.55 \%)$ \\
\hline Complex attacks & 54 & $3(5.56 \%)$ & $40(74.07 \%)$ & $11(20.37 \%)$ \\
\hline
\end{tabular}




\section{Discussion}

This study closely examines complex and simple suicide attacks, exploring the tactical differences between complex suicide attacks and simple suicide attacks in terms of target goal, discriminative lethality and delivery methods. We now discuss our findings concerning our research question in Section 1 and its theoretical underpinnings discussed in Section 2. In each subsection, we begin with our findings on complex suicide attacks in comparison to simple attacks by looking at target goal, discriminative lethality and delivery methods. In this section, we argue that there is evidence that complex suicide attacks reduce civilian casualties. We show evidence that suicide vehicle bombs remain the most popular devices used in complex suicide operations. Whilst complex suicide attacks were introduced to improve precision and soften the layers of security whilst aligning with Al-Qaeda's guidelines in attacking foreign forces, we show evidence that this is not the case, as most of the targets were primarily domestic targets. Finally, we discuss why complex suicide attacks are in decline.

\section{Domestic targets bear the major brunt of complex attacks}

The first element of our research question is whether complex suicide attacks predominantly target foreign entities. An important strand of the empirical literature on suicide terrorism maintains that militants are prompted to use suicide attacks when faced with foreign occupation or military intervention from a foreign power. Pape ${ }^{38}$, Pape and Feldman ${ }^{39}$, Collard-Wexler et al. ${ }^{40}$ and Choi and Piazza ${ }^{41}$ argue that nonstate armed groups notably use terrorist suicide attacks against foreign military occupations.

Based on our data, we find no evidence that there is a significant increase in targeting foreign forces when complex suicide attacks are employed. There was only a 2.9 percent increase on foreign targets by simple suicide attacks (17.5 percent) to 
complex attacks (20.4 percent). Even though the general guidelines outlined by AlQaeda for its affiliates designate the purpose of using complex suicide attacks against foreign targets, the majority of complex suicide attacks were aimed at Somalia's fragile government, accounting for 44.4 percent of all complex attacks. The second most frequent target deployment was against hotels (20.4 percent), especially hotels where Somali government officials and the elite congregated. Indeed, hotels are seen as a token of "Western culture" where there is free mixing between men and women and alcohol is consumed ${ }^{42}$.

Furthermore, hotels are perceived as places which house international aid workers, Western journalists, foreign officials, and members of governments that "fraternise" with the West. Indeed, in a 2017 interview, Al-Shabaab's spokesperson, Sheikh Ali Dheere, justified targeting certain hotels primarily due to their appearance, as some hotels in Mogadishu are built like fortresses, with high surrounding walls ${ }^{43}$. Surprisingly, there were no coordinated attacks against restaurants whilst all recorded suicide attacks against restaurants emanated from simple suicide attacks. The third most frequented target and the theoretical aim of complex attacks are AU bases, accounting for 18.5 percent of total complex attacks.

More broadly, our data reveals that 74.1 percent of all complex suicide attacks were deployed against Somali targets (government institutions, personnel and civilians) whilst only 20.4 percent were deployed against foreign targets (mainly AU bases) revealing no significant shift in the primary target between both modes. Whilst the majority of simple attacks (67.5 percent) were aimed at Somali targets, our data demonstrate that there was an increase of 6.6 percent in complex suicide attacks aimed at domestic targets. This contravenes the strategic objective espoused by Al-Shabaab's spokesperson where he explicitly stated that their primary goal is "...defending our 
nation, religion and dignity" ${ }^{44}$ which logically would see a decrease in attacks against domestic targets. However, unravelling the rhetoric, Wood, Kathman, and Gent ${ }^{45}$ determine that international interventions carve the tactical behaviour of insurgents and that this behaviour is modified by which side of the conflict the foreign power intervenes in. In scenarios where direct foreign intervention aims to weaken a domestic combatant, Wood and his colleagues argue that VEOs are more likely to attack civilians and to violate human rights and adopt violent non-conventional tactics. For Al-Shabaab to predominately target domestic actors is in harmony with the conventional understanding of the strategic objectives of suicide attacks. Such attacks are aimed at undermining state/local governments, demonstrating their vulnerability, instilling fear amongst the people and portraying the VEO as strong and resolute in order to attract more recruits ${ }^{46}$. However, this strategic objective is based on the assumption that the country does not host an assortment of pro-government foreign troops, which is not the case in Somalia.

Thus, we find that in the case of complex attacks' primary targets, there is an increase in domestic targets when complex suicide attacks are employed. Domestic spaces, not foreign targets, remain the primary theorised intended targets, and this is in line with the targeting patterns of simple suicide attacks. Whilst a significant portion of simple suicide attacks were deployed against international personnel and UN institutions; complex suicide attacks veered towards increasing attacks against mainly domestic actors and AU forces. Consequently, our findings contravene the longstanding assertion by experts that suicide terrorism is mainly aimed at foreign forces ${ }^{47}$.

\section{Complex suicide attacks have a lower civilian casualty rate}

Here we explore the second part of our research question considering whether complex suicide attacks are discriminatively employed to reduce civilian collateral damage from 
simple suicide attacks as outlined in Al-Qaeda's guidelines.

Prior to merging with Al-Qaeda, Al-Shabaab was criticised by Al-Qaeda for its disproportionate targeting of non-combatants. Before adopting complex suicide attacks, Al-Shabaab's track record in conventional suicide attacks had a high civilian casualty rate even though the majority of its suicide operations were aimed at hard targets. This is evident in the fact that for 37 simple suicide attacks conducted between 2006 and 2011, a significant majority (73.72 percent) of the victims were civilians. This has been the case even after the fact that Al-Shabaab incorporated complex suicide attacks as part of its existing modus operandi to reduce civilian casualties. This is manifested in the years between 2013 and 2018, when the majority of fatalities from simple attacks was incurred by civilians ( 85 percent).

Based on our data, we find that for the 54 complex attacks that were conducted by Al-Shabaab, the majority of the fatalities (60 percent) were military and political targets whilst civilians suffered 40 percent of the fatalities. This is in stark contrast to the civilian fatalities caused by simple attacks ( 82 percent) with only 18 percent being military and political targets. Indeed, our data reveals that there is no significant difference in the hard and soft targeting patterns for simple and complex suicide attacks. The complex suicide attacks report a 10 percent increase in targeting hard-to-reach areas whereas there is only 1 percent difference in soft targets between simple and complex suicide attacks. It demonstrates that whilst the hard and soft targeting patterns for both modes are more and less the same, there is a significant reduction of 42 percent in civilian casualties in complex attacks.

More importantly, when analysing complex suicide attacks, our data confirm that the civilian-to-combatant ratio is dramatically reduced, serving as a stabiliser to the high civilian casualties accrued from simple attacks. 
Finally, it's of strategic importance for the group to minimise the civilian casualties as much as possible. One, it aids the group's perennial goal which is to establish itself as a legitimate alternative to any perceived legitimate government. Indeed, by predominantly targeting government personnel or anyone who affiliates with the governing body in civilian spaces, Al-Shabaab aims to erode the credibility and legitimacy of the Somali government, thus exposing its inherent weakness and fragility. Secondly, by avoiding or minimising civilian casualties when conducting complex suicide operations, Al-Shabaab adheres to the guiding principle set forth by Al-Qaeda's general command.

\section{Suicide vehicle bombs remain the most popular delivery system in complex attacks}

In this section, we look at the third element of our research question, which investigates whether complex suicide attacks rely more heavily on motorised weapons such as explosive-laden vehicles, cars or truck bombs, than do simple suicide attacks.

Employing suicide vehicle bombs can enable a numerically and technologically inferior force to strike the enemy using large explosive payloads accurately. Therefore, this is regarded as one of the most popular methods of attack for a variety of VEOs, mainly due to its powerful role as a force multiplier.

Based on our data, we find that for the 54 complex attacks conducted by AlShabaab, 74.07 percent of the operations used suicide vehicle bombs solely as their delivery methods whilst for simple attacks, it was 64.29 percent, revealing a significant increase of 9.78 percent. Both modes relied heavily on suicide vehicle bombs in their attacks. It is worth mentioning that multiple devices (suicide vehicle bombs and personborne IEDs) were adopted to a certain extent in complex suicide attacks (20.37 percent) whilst simple suicide attacks (4.55 percent) shied away from using multiple delivery 
systems. Indeed, suicide vehicle bombs in complex attacks were mainly used against Somali military targets and hotels, and there have been no recorded instances of them being used against foreign targets. However, the case is reversed when it comes to person-borne IEDs. Almost one-third of simple attacks employed person-borne IEDs as part of their delivery systems whilst complex attacks only used person-borne IEDs in 3 instances ( 5.56 percent) as the sole delivery system in their attacks. These three recorded events were conducted in the early years of complex suicide attacks, suggesting that they were proven to be ineffective.

Similarly, although simple attacks have significantly used person-borne IEDs, most of the events were conducted in Al-Shabaab's early years. One plausible explanation for why Al-Shabaab has stopped relying on person-borne IEDs is due to its high failure rate. Indeed, more than half (60.87 percent) of failed simple attacks emanated from events that solely employed person-borne IEDs as their delivery system.

Thus, we find that our analysis of research data confirms that the majority of complex suicide attacks use suicide vehicle bombs (94.44 percent) as a single device or in conjunction with other devices. The increased use of suicide vehicle bombs by AlShabaab is no surprise to the authors, as this tactic served more established terrorist groups like Islamic State, or Daesh, well ${ }^{48}$. It is understood that this tactic is dictated by the nature of asymmetric warfare, where one party has superior capability in weaponry over the other ${ }^{49}$. Some analysts have emphasised the shock value suicide vehicle bombs have in disorienting enemy forces and causing chaos ${ }^{50}$, and others argue that it is the perfect covert delivery system ${ }^{51}$.

Finally, we suspected that suicide vehicle bombs would be used less against soft targets, but all recorded complex suicide attacks against exclusive civilian spots employed suicide vehicle bombs. Even though suicide vehicle bombs require more 
resources, including the acquisition of explosives material, they remain Al-Shabaab's primary delivery system of choice.

\section{Complex suicide attacks on the back foot}

Since the steady implementation of complex attacks in 2013, the yearly attacks have been gradually increasing up until late 2017 when for the first time, they began to decrease. Both simple and complex attacks have been waning, and 2018 data reveals a significant reduction in suicide attacks. The possible reasons why attacks have decreased include public outcry, targeted assassinations and lost territories.

First, Al-Shabaab gains its legitimacy by espousing a cause that involves coercing foreign occupying forces to withdraw from Somalia and the establishment of an Islamic emirate. This sentiment has gained the group many constituents; however, significant trust and support can be eroded through targeting errors. Indeed, when a VEO selects a target that is regarded as illegitimate by their supporters (such as attacking spots frequented by civilians only), the VEO is faced with a significant loss of popular support ${ }^{52}$. Our first possible suggestion is the targeting error that lead to the infamous Zoobe 2017 bombing event. In October 2017, Al-Shabaab launched its most devastating attack at a crowded junction in the centre of Mogadishu. The driver detonated a large suicide vehicle bomb in a heavily populated urban area, recording the highest number of casualties and the deadliest single incident in Somalia to date, with at least 587 victims killed and at least 316 victims wounded. Whilst Al-Shabaab has never publicly claimed responsibility for the Zoobe Junction attack; it is the only actor capable of an assault of that size. This targeting error sparked public outrage and large demonstrations of angry Somalis shouting slogans against Al-Shabaab. Even though this attack is classified as a simple suicide attack, the targeting error had a detrimental effect on all suicide bombing activities conducted by Al-Shabaab. 
Second, as an increasingly prominent tool in the "war on terror" the US government employed drone strikes ${ }^{53}$. Since 2002, the United States has launched 4,788 drone strikes against Al-Qaeda and their affiliates, including Al-Shabaab (The Bureau of Investigative Journalism, 2018). More specifically, In March 2017, the use of American drones in Somalia intensified as low-level commanders were given the authority to designate targets and approve drone strikes. The air campaign has stalled Al-Shabaab's tactical abilities, planted growing mistrust amongst its members, and severely restricted the mobility of its commanders. The introduction of multiple battlefronts, depletion in numbers of foreign fighters, internal divisions and increased level of defections have diminished Al-Shabaab's operational capacity. Since the Zoobe truck-bombing, Al-Shabaab has faced an increasing stream of defections and bettercoordinated counter-insurgency from AMISOM and the Somali security forces.

Third, Al-Shabaab also faces significant financial hardships, especially after significant loss of territory to AMISOM and the Somali National Army (SNA). This includes loss of key seaports (Kismayo, Brava and Merca) which provided them with a constant stream of revenue. This indicates that Al-Shabaab is now cash-starved and financially weakened. The group has to rely on the collection of 'taxes' in the form of zakat, an obligatory Islamic 2.5 per cent of wealth tax, as an alternative source of income to fund its insurgency. However, this has put them at odds and in conflict with poor rural agriculture and livestock farming communities who initially accepted the levy out of the fear of the consequences of not paying. However, they later rejected these taxes and have subsequently taken up arms against Al-Shabaab. In the semiautonomous Hir-Shabelle regional state of Somalia, a tribal group formed a militia, commonly known as Macawisley (sarong-wearing fighters), to reject Al-Shabaab's stringent demands. 
Fourth, the arrival of the Islamic State (ISIS) group in the theatre of Somalia conflict has weakened Al-Shabaab's dominance in the vast Somali territory. This means the group now faces multiple conflicts and adversaries, as well as their traditional enemies, AMISOM and SNA. The presence of an equally determined, militant and deadly contender in Somalia is a new threat faced by Al-Shabaab.

Nevertheless, whilst complex attacks are lower in number than simple attacks, it has a greater bearing on Al-Shabaab's long-term goal to destabilise the Somali federal government. Even though it is in decline, its efficacy to sustain Al-Shabaab's relevancy is still significant and without a new approach, its resurgence is inevitable.

\section{Conclusion}

This paper has sought to contribute to the existing literature on suicide terrorism. This paper provides the first in-depth look at the phenomenon of complex suicide attacks. Using Al-Shabaab as a case study, the authors explore the tactical differences between complex suicide attacks and simple suicide attacks in terms of target goal, discriminative lethality and delivery methods. Our findings offer some insightful implications for understanding the use of complex suicide attacks.

First, it reveals that the phenomenon of complex suicide attacks reduces civilian casualties, in general revealing a low rate of civilian to combat deaths. This reduction in civilian deaths is a strategic effort to chip away the legitimacy of the Somali government and for the group to offer itself as a viable alternative of legitimate governance to the Somali government. Further, reducing civilian casualties keeps the group's patron, Al-Qaeda, satisfied as it adheres to the general guidelines it prescribed.

Second, suicide vehicle bombs remain the most popular devices used in complex and simple suicide attacks. 
Third, Al-Shabaab espouses that its main targets are AMISOM and other international personnel, however, Somali targets bear the brunt of the majority of all complex suicide attacks, revealing no change in targeting patterns between simple and complex attacks, aside from increased frequency.

Fourth, our data suggest that Al-Shabaab is on the back foot, revealing a sharp drop in complex attacks since 2017. Despite this, Al-Shabaab remains a potent threat and is still able to carry out deadly complex attacks to achieve its strategic goals, albeit at low frequency. A new approach is required.

The findings of this paper shed a light on the phenomenon of complex suicide attacks which hitherto has been absent in academic literature. They inform security and intelligence agencies and other policymakers the rationale behind the choice, use and effect of varied modes of suicide bombing attacks against identified targets. These findings have the potential to make an important contribution to the development of effective counter-terrorism strategies informed by prudent research and evidence.

However, we recognise the possible limitation of this research including its lack of examining the extent to which the current Somali federal government is capitalising on these apparent weaknesses of Al-Shabaab. Whilst we see the merits of examining this issue, we take the view that it is outside the scope of our investigation. Another limitation emanating from our paper is the adoption of a single VEOs as a case study to explore the phenomenon of complex suicide attacks.

Nevertheless, future research might explore the effectiveness of detecting, aborting and preventing Al-Shabaab terrorist suicide bombing activities. An examination is warranted for future research to test whether this paper's findings can be observed in other groups who distinctively employ complex suicide attacks. 


\section{Notes}

1 Patrick Kimunguyi, "Terrorism and Counter Terrorism in East Africa," In Understanding Terrorism From an Australian Perspective: Radicalisation, De-Radicalisation and Counter- Radicalisation, edited by Joe Iiardi Greg Barton, Pete Lentini, Simon Moss (Melbourne: Global Terrorism Research Centre, Monash University, 2011), 1-23.

2 Jason Warner and Ellen Chapin, "Targeted Terror: The Suicide Bombers of Al-Shabaab," Combating Terrorism Center at West Point. (West Point, 2018).

3 ACLED, "Al Shabaab and Boko Haram: Patterns of Violence - ACLEDDATA - Crisis," 2017, http://www.crisis.acleddata.com/al-shabaab-and-boko-haram-patterns-of-violence/.

4 Stanley Ehiane, "Strengthening the African Union (AU) Counter-Terrorism Strategy in Africa : A Re-Awakened Order," Journal of African Union Studies 7, no. 2 (October 12, 2018): 109-21, https://doi.org/10.31920/2050-4306/2018/v7n2a6.

5 Freedom C Onuoha, "Westgate Attack: Al-Shabaab's Renewed Transnational Jihadism," Al Jazeera Center for Studies (2013), http://studies.aljazeera.net/ResourceGallery/media/ Documents/2013/11/11/20131111123040955734Kenya.pdf.

6 Ioannis Gatsiounis, “After Al-Shabaab," Current Trends in Islamist Ideology, no. 14 (September 2012): 74-89, http://www.hudson.org/content/researchattachments/attachment/1117/ 20130124 ct14gatsiounis.pdf.

7 United Nations High Commission for Human Rights and United Nations Assistance Mission for Iraq, "Report on the Protection of Civilians in Armed Conflict in Iraq : 1 May - 31 October 2015" (Geneva, 2016).

8 Richard Downie, “Al Shabaab: How Great a Threat?," Hampton Roads International Security Quarterly (Washington, 2013), http://securityassistance.org/sites/default/files/HHRG-113- FA00Wstate-DownieR-20131003.pdf. Daniel E. Agbiboa, “Ties That Bind: The Evolution and Links of Al-Shabab," Round Table 103, no. 6 (November 2, 2014): 581-97, https://doi. org/10.1080/00358533.2014.988028.

9 Stig Jarle Hansen, Al-Shabaab in Somalia: The History and Ideology of a Militant Islamist Group, 
2005-2012 (London: Hurst, 2013)., https://doi.org/10.1093/acprof:oso/9780199327874. 001.0001;

Gatsiounis, "After Al-Shabaab."

10 Brendon J. Cannon and Dominic Ruto Pkalya, "Why Al-Shabaab Attacks Kenya: Questioning the Narrative Paradigm," Terrorism and Political Violence, 31, no. 4 (2019): 836-52. https:// doi.org/10.1080/09546553.2017.1290607.

11 Warner and Chapin, "Targeted Terror: The Suicide Bombers of Al-Shabaab."

12 Paul D. Williams, "Subduing Al-Shabaab: The Somalia Model of Counterterrorism and Its Limits," Washington Quarterly 41, no. 2 (2018): 95-111, https://doi.org/10.1080/0163660X. 2018.1484227; Paul Joosse, Sandra M. Bucerius, and Sara K. Thompson, "Narratives and Counternarratives: Somali-Canadians on Recruitment as Foreign Fighters to Al-Shabaab," British Journal of Criminology 55, no. 4 (2015): 811-32, https://doi.org/10.1093/bjc/azu103.

13 Audrey Kurth Cronin, "Terrorists and Suicide Attacks," CRS Rept. for Cong. Order Code RL32058, 2003; Alec D. Barker, "Improvised Explosive Devices in Southern Afghanistan and Western Pakistan, 2002-2009," Studies in Conflict and Terrorism 34, no. 8 (August 2011): 600620, https://doi.org/10.1080/1057610X.2011.582630; Adam Dolnik, Understanding Terrorist Innovation: Technology, Tactics and Global Trends, Routledge, Contemporary Terrorism Studies (London: Routledge, 2007), https://doi.org/10.4324/9780203088944.

14 Adam Dolnik, Understanding Terrorist Innovation: Technology, Tactics and Global Trends.

15 Katherine R. Seifert and Clark McCauley, "Targets Can Reveal Insurgent Motives and Priorities," Terrorism and Political Violence 26, no. 5 (2014): 803-20, https://doi.org/10. 1080/09546553.2013.778198; Edgar Alfonseca, "Strategic Logic of Suicide Terrorism," Journal of Conflict Resolution 2001, no. 2003 (2012): 1-4.

16 Bruce Hoffman, Inside Terrorism, International Journal (New York: Columbia University Press, 2006), 132.

17 Alfonseca, "Strategic Logic of Suicide Terrorism."

18 Robert A. Pape, "The Strategic Logic of Suicide Terrorism," American Political Science Review 97, no. 3 (2003): 343-61, https://doi.org/10.1017/S000305540300073X.

19 Mia Bloom, Dying to Kill : The Allure of Suicide Terror (New York: Columbia University Press, 2005).

20 Dolnik, Understanding Terrorist Innovation: Technology, Tactics and Global Trends; Martha Crenshaw, "The Causes of Terrorism," Comparative Politics 13, no. 4 (2006): 379, https://doi. org/10.2307/421717; Spencer Tucker, Encyclopedia of Insurgency and Counterinsurgency : $A$ 
New Era of Modern Warfare (Santa Barbara: ABC-CLIO, 2013).

21 David C. Rapoport, "Fear and Trembling: Terrorism in Three Religious Traditions," American Political Science Review 78, no. 3 (1983): 658-77, https://doi.org/10.2307/1961835.

22 Eli Berman and David D. Laitin, "Religion, Terrorism and Public Goods: Testing the Club Model," Journal of Public Economics 92, no. 10-11 (2008): 1942-67, https://doi.org/10.1016/j. jpubeco.2008.03.007.

23 Peter S. Henne, "The Ancient Fire: Religion and Suicide Terrorism," Terrorism and Political Violence 24, no. 1 (2012): 38-60, https://doi.org/10.1080/09546553.2011.608817, https://doi. org/10.1080/09546553.2011.608817.

24 Victor Asal and R. Karl Rethemeyer, "The Nature of the Beast: Organizational Structures and the Lethality of Terrorist Attacks," Journal of Politics 70, no. 2 (2008): 437-49, https://doi.org/ $10.1017 / \mathrm{S} 0022381608080419$.

25 "The Logic of Suicide Terrorism," RAND Corporation, 2003, https://www.rand.org/pubs/ reprints/RP1187.html.

26 Nurit Kliot and Igal Charney, “The Geography of Suicide Terrorism in Israel,” GeoJournal 66, no. 4 (2006): 353-73, https://doi.org/10.1007/s10708-006-9034-z.

27 Mark Ensalaco, Middle Eastern Terrorism: From Black September to September 11 (Philadelphia: University of Pennsylvania Press, 2010).

28 Robert A. Pape, "Dying to Win: The Strategic Logic of Suicide Terrorism," in The Theory and Practice of Islamic Terrorism (New York: Palgrave Macmillan US, 2008), 129-32, https://doi. org/10.1057/9780230616509_18.

29 Ibid.

30 Charlinda Santifort-Jordan and Todd Sandler, "An Empirical Study of Suicide Terrorism: A Global Analysis," Southern Economic Journal 80, no. 4 (April 1, 2014): 981-1001, https://doi. org/10.4284/0038-4038-2013.114; Seung Whan Choi and James A. Piazza, "Foreign Military Interventions and Suicide Attacks," Journal of Conflict Resolution 61, no. 2 (February 10, 2017): 271-97, https://doi.org/10.1177/0022002715576575.

31 Ayman Al-Zawahiri, “General Guidelines for Jihad,” As-Sahab Media, 2013.

32 Ibid.

33 Bin Laden, "Letter to Abu Muhammed Salah," Bin Laden's Bookshelf, Office of the Director of National Intelligence, 2010, 43. 
34 Adam Dolnik, Understanding Terrorist Innovation: Technology, Tactics and Global Trends, Routledge, Contemporary Terrorism Studies (London: Routledge, 2007), https://doi.org/10. 4324/9780203088944; Mary. Kaldor, New and Old Wars : Organized Violence in a Global Era (Polity Press, 1999).

Hoffman, Inside Terrorism.

Rahn K. Bailey et al., "Suicide: Current Trends,” Journal of the National Medical Association 103, no. 7 (2011): 614-17, https://doi.org/10.1016/S0027-9684(15)30388-6.

37 Steven Metz and Raymond Millen, "Intervention, Stabilization, and Transformation Operations: The Role of Landpower in the New Strategic Environment," Parameters 35, no. 1 (2005): 41, https://apps.dtic.mil/docs/citations/ADA486422.

38 Robert A Pape, "The Strategic Logic of Suicide Terrorism”, American Political Science Review 97, no. 3 (2003): 343-61, https://doi.org/10.1017/S000305540300073X; Robert A. Pape, "Dying to Win: The Strategic Logic of Suicide Terrorism," in Theory andPractice of Islamic Terrorism (New York: Palgrave Macmillan US, 2008), 129-32, https://doi.org/10.1057/9780230616509_18.

Robert A. Pape and James K. Feldman, Cutting the Fuse: The Explosion of Global Suicide Terrorism and How to Stop It (Chicago: University of Chicago Press, 2010).

Simon Collard-Wexler, Costantino Pischedda, and Michael G. Smith, "Do Foreign Occupations Cause Suicide Attacks?” Journal of Conflict Resolution 58, no. 4 (June 13, 2014): 625-57, https://doi.org/10.1177/0022002713478558.

41 "Foreign Military Interventions and Suicide Attacks."

42 Scott Stewart, "AQAP: Paradigm Shifts and Lessons Learned," faculty.uml.edu, 2009, http:// faculty.uml.edu/jyurcak/44.248/ADMIN/Articles/AQAP.pdf.

Dalsoor, Wareysi Qaybtii laad: Sheekh Cal Dheere - Interview Part One: Sheekh Cali Dheere [Video File], 2017.

44 Ibid.

45 Reed M Wood, Jacob D Kathman, and Stephen E Gent, "Armed Intervention and Civilian Victimization in Intrastate Conflicts," Journal of Peace Research 49, no. 5 (September 28, 2012): 647-60, https://doi.org/10.1177/0022343312449032.

Martha Crenshaw, "The Debate over 'New' vs. 'Old' Terrorism," in Values and Violence (Dordrecht: Springer Netherlands, 2008), 117-36, https://doi.org/10.1007/978-1-4020-8660- 1_8; Dolnik, Understanding Terrorist Innovation: Technology, Tactics and Global Trends.

47 Robert A. Pape, "Dying to Win: The Strategic Logic of Suicide Terrorism," in The Theory and 
Practice of Islamic Terrorism (New York: Palgrave Macmillan US, 2008), 129-32, https://doi. org/10.1057/9780230616509_18.

48 Hugo Kaaman, "Car Bombs as a Weapons of War: ISIS's Development of SVBIEDs, 2014-19” (Washington, 2019), https://www.mei.edu/publications/car-bombs-weapons-war-isiss-develop mentsvbieds-2014-19.

49 M R Sudhir, “Asymmetric War : A Conceptual Understanding,” CLAWS, no. Summer (2008): 5866.

50 Michael Knights, “ISIL's Political-Military Power in Iraq," Institute for the Study of War, 2013, https://ctc.usma.edu/app/uploads/2014/09/CTCSentinel-Vol7Iss84.pdf.

51 James Lutz, Brenda Lutz, and Brenda Lutz, Global Terrorism (London: Routledge, 2013), https://doi.org/10.4324/9780203731321.

52 Cronin, "Terrorists and Suicide Attacks."

53 Daniel. Klaidman, Kill or Capture: The War on Terror and the Soul of the Obama Presidency (Boston: Houghton Mifflin Harcourt, 2012). 